Resumido por el autor, Merkel Henry Jacobs.

La aclimatación como factor capaz de afectar el punto en que acaece la muerte de los organismos sometidos a temperaturas elevadas

Si se conoce el tiempo necesario para producir la muerte de las larvas de estrella de mar sometidas a una cierta temperatura elevada, el tiempo necesario para producir el mismo efecto a cualquier otra temperatura puede determinarse con un grado muy aproximado de exactitud. En general, el coeficiente de temperatura es próximamente 2 para cada elevación térmica de $1^{\circ} \mathrm{C}$. El coeficiente de temperatura de Paramoecium bajo condiciones semejantes está mucho más sujeto a variación, pudiendo ser 3 o mas algunas veces, en otras ocasiones menos de 2 . Durante la elevación gradual de la temperatura en las larvas de estrella de mar, se suman los efectos nocivos de todas las temperaturas por las cuales han pasado durante dicha elevación y mueren casi en el mismo momento en que se alcanza el punto en que deben morir teóricamente como resultado de la suma de todos los efectos nocivos. El punto en que tiene lugar la muerte del animal es tanto más bajo cuanto más lenta es la elevación de la temperatura. En Paramecium, por el contrario, el punto en que el animal muere es tanto más alto cuanto más lenta es la elevación de la temperatura. En esta especie la aclimatación modifica las relaciones tan simples que se presentan en la larva de la estrella de mar. El grado de aclimatación en una forma determinada puede estimarse cuantitativamente determinando el "exceso de resistencia" (surplus resistance) mediante el método que el autor describe en el trabajo. Medido en términos de cantidad de efectos nocivos necesarios para producir un resultado fatal, este "exceso de resistencia" es próximo a cero en las larvas de estrella de mar, mientras que en Paramecium llega a ser 45. Estas cifras dan una medida aproximada de la capacidad de adaptación a temperaturas más y más elevadas en las dos especies mencionadas.

Translation by Dr. José F. Nontdez,

Columbia University. 
AUTHOR'S ABSTRACT OF THIS PAPER ISSUED

BY THE BIBLIOGRAPHIC SERVICE, DECEMBER 9

\title{
ACCLIMATIZATION AS A FACTOR AFFECTING THE UPPER THERMAL DEATH POINTS OF ORGANISMS
}

\author{
M. H. JACOBS \\ University of Pennsylvania
}

\section{INTRODUCTION}

The question of the effects produced on organisms by high temperatures is one which has received the attention of biologists for many years. The older workers were interested chiefly in the determination of the so-called 'upper thermal death points.' A résumé of their observations is given by Davenport ('97). In more recent times, the importance of the time factor, overlooked in this earlier work, has been recognized, and modern investigators have been more concerned with 'temperature coefficients' (Pütter, '14; Kanitz, '15) and with the possible causes of injury at the elevated temperatures. In most of the recent, and in practically all of the older work, however, a factor not sufficiently taken into account is the method by which the temperatures used in the experiments have been attained.

There are, in general, three chief ways of bringing an organism to a given high temperature. 1) The change may be practically instantaneous, as, for example, if a minute animal in a small quantity of water is suddenly expelled from a pipette into a large volume of water at the required temperature. 2) The change may be gradual, but uniform, as, for example, if the animal is placed in a vessel of water at room temperature, and heat applied in such a way that the rise per minute remains constant until the desired point is reached. 3) The change may be gradual, but at a constantly decreasing rate, as, for example, if the animal is placed in a test-tube containing water at room temperature, and the test-tube is then plunged into a large 
vessel of water which is kept at the final temperature. In this case, the rise is at first rapid, becoming progressively slower and slower-being represented, in fact, by the logarithmic curve of Newton's well-known 'law of cooling bodies,' except that the temperature in this case is increasing instead of decreasing.

Of the three methods mentioned, the third is generally undesirable, partly because of the greater difficulty of making allowance for a constantly changing rate of temperature increase, partly on account of the difficulty of determining the exact time when the desired temperature has been reached, and chiefly because of the great length of exposure (due to the slow rate of change as the end point is approached) to temperatures whose effects are almost as great as those of the one finally attained. Method 1, in exact work, is applicable only to very small organisms, since any attempt to apply it to large ones results in securing essentially the effects of method 3 , with the additional disadvantage that on account of the slow conduction of heat, different parts of the body reach the final temperature at different times. Method 2, therefore, which involves raising the temperature at a known rate until the desired point has been reached, is the most suitable one for all except very small organisms and has been most frequently employed. But in the past very little effort has been made to take into account the influence on the final result of the rate at which the temperature is raised. That this factor is probably of importance is obvious, but to predict in advance in what direction and to what extent it will operate is not always an easy matter.

Suppose, for example, that in a certain experiment a lot of organisms are brought in the course of ten minutes from room temperature to $40^{\circ} \mathrm{C}$. and kept at the latter point until death occurs. Would the time required to cause death at $40^{\circ}$ be greater, or less, if in another similar experiment the preliminary rise were allowed to occupy thirty minutes instead of ten? It might be argued, on the one hand, that the slower rate would be less favorable to the organisms than the rapid one because of the greater length of exposure to temperatures below $40^{\circ}$, but still sufficiently high to produce in the aggregate considerable 
injury before the final temperature had been attained. The possibility exists, however, on the other hand, that the slower rate would be more favorable than the rapid one in giving greater opportunity for adjustment or acclimatization to occur. Which of these two alternatives is the correct one for a given form can, as a matter of fact, be decided only by experiment.

In the present paper a method is suggested for determining this point and for dealing quantitatively with certain other aspects of the general problem of acclimatization. The writer wishes to express his indebtedness to Prof. F. R. Lillie for kindly placing at his disposal on several occasions the facilities of the Marine Biological Laboratory at Woods Hole and to Mr. Francis $\mathrm{H}$. Adler for assistance in making certain of the observations on which the paper is based.

\section{MATERIAL AND APPARATUS}

In the experiments to be described, the use of both methods 1 and 2 was necessary for the quantitative estimation of the extent to which acclimatization occurs. For this reason, only small organisms were employed, starfish larvae eighteen to forty-eight hours old and Paramecium caudatum being the ones chosen. The medium in which they were heated was for the starfish larvae fresh sea-water and for Paramecium, in most cases, the natural culture fluid filtered to remove all animals. It was recognized that the complex nature of the culture fluid might introduce undesirable complicating factors, but preliminary - experiments showed that, as a matter of fact, distilled water, which would naturally have been preferred on account of its uniform composition and in which the animals lived normally at room temperature for days, was quite unsuitable for sudden exposures to high temperatures, the animals dying far more quickly in it than in their own culture medium, and the results obtained being markedly irregular. That at least part of the effect of the distilled water was of an osmotic nature was shown by the fact that the addition to the same water of slight amounts of neutral salts or even of cane sugar made it considerably less injurious. It 
is perhaps possible also that the absence of appreciable amounts of 'buffer substances' may have been another of the factors concerned, since there is some evidence of the production of abnormal amounts of acids at elevated temperatures. At any rate, it was found that apparently the most reliable results could be obtained when normal culture fluid was used, although very similar results were also secured in some cases with pond-water when the animals had been kept in it for at least twelve hours previous to the experiments.

The apparatus employed was of a simple nature. It consisted of a 2-liter beaker, used as a water-bath, supported on a stand and heated from below by an alcohol lamp whose position could be altered to furnish much or little heat as desired. In the beaker were placed a number of test-tubes containing enough water or culture fluid to make them float upright. The transparency of the whole apparatus was found to be of advantage, not only in favoring such manipulations of the material as were necessary, but in making it possible to observe the visible effects of the high temperature on, for example, the movements of the animals.

When a sudden exposure was desired, the water in the waterbath and in the test-tubes was first allowed to assume the proper temperature, and then a considerable number of the organisms were taken in the smallest possible quantity of water in a capillary pipette (this being very easy in the case of both of the animals used on account of their habit of collecting in a dense ring around the edges of the culture jar) and suddenly forced into one of the test-tubes in such a way as to insure thorough mixing. The. quantity of water used was so small as practically not to affect the temperature of the water in the test-tube, calculation showing that the momentary lowering of its temperature, which was not even indicated on an ordinary mercurial thermometer, could not have been, as a rule, more than $0.1^{\circ} \mathrm{C}$. After this sudden introduction to the temperature of the experiment the organisms were either all allowed to remain in the test-tube for the required length of time and then suddenly poured into sufficient cool water to bring them back immediately to within their normal 
range of temperature, or they were removed, a few at a time, at the proper intervals with a capillary pipette.

Where a gradual rate of temperature increase was desired, the same general methods were employed except that the animals, instead of being introduced suddenly into the test-tubes, were placed in them at room temperature and the whole apparatus was heated at the desired rate, samples of the animals being removed, usually at half-degree intervals. The animals, whether suddenly or gradually exposed, were kept under observation after removal in Syracuse watch-glasses until they had either died or recovered, which in some cases required as much as twenty-four hours, although as a rule their behavior when first examined left little doubt as to the ultimate outcome of the experiment.

\section{METHOD OF ESTIMATING ACCLIMATIZATION}

The extent to which acclimatization occurs during a slow rise of temperature may theoretically be estimated by first finding by method 1 (where there is no opportunity for preliminary acclimatization to occur) the amount of injury inflicted in unit time at the various temperatures passed through during the rise, and in them adding together these separate injuries, beginning with the lowest temperature, and taking into account the duration of each, until a total just sufficient theoretically to cause death is arrived at. The point at which this total is reached is compared with the observed death point in the case of the gradual rise. If the two points practically coincide, it may be said that there is no evidence of acclimatization. If, on the other hand, the observed death point is higher than the calculated one, the presumption is that acclimatization has occurred and the amount of the latter can be estimated, roughly at least, in quantitative form. It must be remembered, of course, that the calculated death point cannot be determined by merely adding the theoretical amounts of injury at, for example, $34^{\circ}, 35^{\circ}, 36^{\circ}$, etc., since the rise does not proceed by a series of sudden jumps, but continuously. Since, however, the relation of 
the amount of injury inflicted in unit time at any one temperature to that inflicted in the same time at any other temperature is, for a certain range, in the forms studied, governed by a simple mathematical law, it is possible by making observations at a few selected temperatures, and thus determining the necessary constants, to calculate the theoretical effect of a continuous change of temperature at any desired rate. The details of the method will be made clearer in the following sections where the actual experiments are discussed.

\section{EXPERIMENTS ON STARFISH LARVAE}

Since the results obtained with starfish larvae are simpler than those with Paramecium, they may be considered first. In table 1 are given the lengths of exposure found to cause death when the animals were suddenly subjected by method 1 to the temperatures in question. The fatal exposure in each case is

\section{TABLE 1}

Times required to kill approximately one-half of the individuals of starfish larvae. when suddenly subjected to various temperatures

\begin{tabular}{|c|c|c|c|c|c|c|c|}
\hline \multirow{2}{*}{ 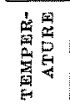 } & \multicolumn{2}{|c|}{ JUNE 16,18 HOURS OLD. } & \multicolumn{2}{|c|}{ JUNE 21,48 HOURS OLD } & \multicolumn{2}{|c|}{ JUNE 22,24 \#OURS OLD } & \multirow{2}{*}{$\begin{array}{c}\text { JoNe } 23, \\
24 \text { HoURS OLD } \\
\text { Fatal exposure }\end{array}$} \\
\hline & Fatal exposure & $\mathrm{Q}_{2}$ & Fatal exposure & $Q_{1}$ & Fatal exposure & $Q_{1}$ & \\
\hline $\operatorname{deg} . C$. & & & & & & & \\
\hline 40 & 8 seconds & & 10 seconds & & & & \\
\hline 39 & 15 seconds & 1.9 & 18 seconds & 1.8 & & & \\
\hline & & 1.5 & & 1.7 & & & \\
\hline 38 & 23 seconds & 2.2 & 30 seconds & 1.7 & & & \\
\hline 37 & 50 seconds & 15 & 50 seconds & 10 & 45 seconds & 00 & 35 seconds \\
\hline 36 & 1.25 minutes & & 95 seconds & & 1.5 minutes & & \\
\hline 35 & 2.75 minutes & 2.2 & 3.5 minutes & 2.2 & 4 minutes & 2.7 & 2.5 minutes \\
\hline 34 & 7 minutes & 2.5 & 8 minutes & 2.3 & 8 minutes & 2.0 & \\
\hline 33 & 15 minutes & 2.1 & & & 20 minutes & $\begin{array}{l}2.0 \\
2.3\end{array}$ & 13 minutes \\
\hline 32 & & . & & & 45 minutes & & 30 minutes \\
\hline
\end{tabular}


taken somewhat arbitrarily, as the time required to produce injuries from which approximately half of the individuals failed to recover. The actual death of the animals, according to the temperatures employed, may occur in from a few minutes to twenty-four hours or more after restoration to normal conditions. Undoubtedly such differences are in certain respects significant, but for purposes of immediate comparison they may be disregarded and the degree of injury which is just sufficient ultimately to lead to death, regardless of the time required, may be accepted as the most satisfactory available criterion. It may be mentioned that the starfish gastrulae obtained from a single lot of eggs show little individual variation; the fatal exposure is very nearly the same for all. In this respect they differ from Paramecium in which the individual differences are large.

It will be noticed in table 1 that the time required to produce fatal injury at any temperature bears a fairly definite relation to the time required at other temperatures. Thus, at $34^{\circ}$, for example, about twice as long a time is required as at $35^{\circ}$ and about one-half as long a time as at $33^{\circ}$. Expressed in mathematical symbols,

$$
\frac{\mathrm{L}_{\theta}}{\mathrm{L}_{\theta+1}}=\mathrm{Q}_{1}=2
$$

where $\mathrm{L}$ denotes the length of life, $\theta$ the temperature, and $\mathrm{Q}_{1}$ the temperature coefficient for a change of one degree. Values of $Q_{1}$ are given in alternate columns of table 1. The general average of all of the values of $Q_{1}$ is 2.1. This value agrees closely with that found, for example, by Loeb ('08) for the eggs of Strongylocentrotus and Moore ('10) for Tubularia crocea.

These results may also be stated in another form (table 2). The amount of injury $\left(\mathrm{I}_{\theta}\right)$ inflicted at the temperature $\theta$ by an exposure of unit time (one minute) can be expressed in quantitative form by taking as unity the amount of injury just sufficient to produce death. Thus at $38^{\circ}$, in the series selected for table 2 , where an exposure of twenty-three seconds is necessary to cause death, $I_{38^{\circ}}=2.6$; in the same way $I_{34^{\circ}}=0.14$; and the other values are given in column 2 of table 2 . The mathematical 
TABLE 2

Theoretical amounts of injury inflicted on starfish larvae at various temperatures. The fatal exposures are taken from column 1 of table 1

\begin{tabular}{c|c|c}
\hline TEMPERATURE & TOTAL EXPOSERE & INJURY IN UNIT TME \\
\hline deg. C. & seconds & \\
40 & 8 & 7.5 \\
39 & 15 & 4.0 \\
38 & 23 & 2.6 \\
37 & 50 & 1.2 \\
36 & 75 & 0.8 \\
35 & 165 & 0.36 \\
34 & 420 & 0.14 \\
33 & 900 & 0.07 \\
\hline
\end{tabular}

relation that exists between the amounts of injury inflicted in unit time at different temperatures is

$$
\mathrm{I}_{\mathrm{p}}=\mathrm{I}_{0} \mathrm{Q}_{1}^{\mathrm{p}}
$$

where $I_{0}$ is the amount of injury inflicted at the temperature chosen as the standard for comparison, and $I_{p}$ the amount inflicted at any other temperature separated from the first one by $p$ degrees. If the second temperature is lower than the first, $p$, of course, has a negative sign. Of the two constants in the above expression, $Q_{1}$ may in general be taken for starfish larvae with sufficient accuracy as equal approximately to 2, and $I_{0}$ may be determined experimentally for a given lot of organisms for any convenient temperature, preferably a rather low one, as the percentage of error is then less. Having these two constants, it is possible to calculate not only the amount of injury that would be inflicted by an exposure of any length to any temperature to which the above equation applies, but likewise the amount of injury that ought theoretically to be inflicted during a gradual rise from room temperature to any desired temperature. In the latter case, the amount of injury would be represented graphically by the area of the curve:

$$
\mathrm{y}=\mathrm{a} \mathrm{Q}_{1}^{\mathrm{x}}
$$


between the limits $\mathrm{x}=-\mathrm{b}$ (room temperature) and $\mathrm{x}=\mathrm{p}$ (the highest temperature attained); $b$ and $p$, of course, being measured from the temperature selected as the point of comparison. The constant $a$ is the amount of injury, $I_{0}$, inflicted in unit time at this temperature. The area of the curve, $\mathrm{A}$, which represents the total injury, I, therefore is:

$$
A=I=a \int_{-b}^{p} Q_{1}^{x} d x=a\left(\frac{Q_{1}^{p}}{\log _{e} Q_{1}}-\frac{Q_{1}^{-b}}{\log _{e} Q_{1}}\right)
$$

Since $b$ (the number of degrees the room temperature lies below the temperature chosen for comparison) is relatively large, the second half of the expression within the parentheses becomes negligibly small and may be disregarded. This is equivalent to calculating the injury that would be inflicted in a rise from an infinitely low temperature instead of from room temperature, but this amounts to practically the same thing, since even considerably above room temperature the injury inflicted in any ordinary time has ceased to be appreciable.

If instead of raising the temperature at the rate of one degree per minute as implied in the calculation just given, the rate had been slower, say one degree in $t$ minutes, the right-hand side of the equation would have to be multiplied by $t$. The general expression therefore for the area, $A$, which represents the total injury, $I$, inflicted up to the temperature $\mathrm{p}^{\circ}$ when the rate of rise is one degree in $t$ minutes becomes (when $a$ is replaced by its equivalent $I_{9}$ ):

$$
I=t I_{0} \cdot \frac{Q_{1}^{p}}{\log _{\mathrm{e}} Q_{1}}
$$

In the case of starfish larvae where $Q_{1}$ is equal to approximately 2.0 and $\log _{\mathrm{e}} Q_{1}$ therefore to approximately 0.7 we have finally:

$$
\mathrm{I}=\mathrm{t} \mathrm{I}_{0} \cdot \frac{2^{\mathrm{p}}}{0.7}
$$

In case it is desired to know how high the temperature would have to be raised to inflict just fatal injury, it is only necessary 
to substitute for I the numerical vale 1.0 and solve the equation for p. In such cases (taking $\log _{10} 2=0.3$ )

$$
\mathrm{p}=\frac{\log _{10}\left(\frac{0.7}{\mathrm{tI}}\right)}{0.3}
$$

The results of applying this method to a gradual and regular rate of temperature increase in the case of starfish larvae are shown in table 3 . In the first column is given the rate at which the temperature was raised, in the second the observed death point, and in the third the point at which death ought theoretically to have occurred (i.e., the point at which the area enclosed by the curve becomes unity) when the value of the constant, $Q_{1}$, was taken as equal to 2 (this value holding approximately for all of the starfish larvae studied). The value of $I_{0}$, which varies somewhat for different lots of larvae according to age, etc., was determined especially for the animals used in these experiments, and was found to be 0.05 at the temperature $\left(33^{\circ} \mathrm{C}\right.$.) chosen for comparison.

It must be recognized, of course, that for the portion of the curve between room temperature and $32^{\circ}$, no exact observations are available, and it is uncertain to what extent the above equation applies to it. But the area of this portion of the curve is in any case so small as compared with that above $32^{\circ}$ that the final result would be little affected even if a different relation were

TABLE 3

Temperatures at which death of starfish larvae occurred after varying rates of temperature increase from a starting point of approximately $20^{\circ} \mathrm{C}$.

\begin{tabular}{|c|c|c|c|}
\hline $\begin{array}{l}\text { RATE OF TEMPERATURE } \\
\text { INCREASE IN } \\
\text { DEGREDS PER MINUTE }\end{array}$ & OBSERYED DEATH TEMPERATURE & $\begin{array}{c}\text { THFORATI- } \\
\text { CAL DEATIF } \\
\text { TEMPERA- } \\
\text { TURE } \\
\text { CALCULATED } \\
\text { FROM } \\
\text { Q1 }=2.0\end{array}$ & $\begin{array}{c}\text { THKORETT- } \\
\text { CALDEATHE } \\
\text { TEMPIRA- } \\
\text { TURE } \\
\text { CALCUIATED } \\
\text { FROMI } \\
Q_{ \pm}=2.2\end{array}$ \\
\hline $1^{\circ} \mathrm{C}$. in 1.8 minutes & About one-third dead at $36.0^{\circ}$ & $36.0^{\circ}$ & $35.8^{\circ}$ \\
\hline $1^{\circ} \mathrm{C}$. in 4 minutes & $35.0^{\circ}$ & $34.8^{\circ}$ & $34.8^{\circ}$ \\
\hline $1^{\circ} \mathrm{C}$. in 5 minutes & $34.5^{\circ}$ & $34.5^{\circ}$ & $34.5^{\circ}$ \\
\hline $1^{\circ} \mathrm{C}$. in 8 minutes & All living at $33.5^{\circ}$, all dead at $34.0^{\circ}$ & $33.8^{\circ}$ & $33.9^{\circ}$ \\
\hline
\end{tabular}


shown to hold in this region. It may also be noticed that for the region from $32^{\circ}$ to the point of death in these particular experiments the value of $Q_{1}$ is in general higher than 2.0, the approximate average value for the whole range of temperature studied. In the last column of table 3 , the theoretical death temperature is therefore calculated for comparison from the value, $\mathrm{Q}_{1}=2.2$. It will be noticed that in either case the calculated death temperature lies within a few tenths of a degree of that actually observed, and the amount of acclimatization that has occurred, if any, is consequently extremely small. In similar experiments on Paramecium, immediately to be described, the difference may amount to several degrees.

\section{EXPERIMENTS ON PARAMECIUM CAUDATUM}

In the case of Paramecium, the results are more complicated. In the first place, there is considerably more cultural and racial variation in the length of life at any given temperature (determined by method 1) than in the case of starfish larvae where the results, on the whole, seem to be remarkably uniform. This is shown in table 4 where some of the results obtained with this form are summarized.

The figures in columns 6 and 7 and probably in column 1 are for the three-vacuoled race described by Hance ('15, '17), which

TABLE 4

Times required to kill approximately one-half of the individuals of Paramecium caudatum of different races at different temperatures

\begin{tabular}{|c|c|c|c|c|c|c|c|}
\hline $\begin{array}{c}\text { TEMPERA- } \\
\text { TURE }\end{array}$ & RACE 1 (?) & RACE 2 & RACE 3 & RACE 4 & RACE 5 & RACE 6 & RACE 6 \\
\hline $\begin{array}{c}\text { deg. } C \text {. } \\
43 \\
42 \\
41 \\
40 \\
39 \\
38 \\
37 \\
36\end{array}$ & $\begin{array}{r}30.0 \text { sec. } \\
1.5 \text { min. } \\
4.5 \text { min. } \\
13.0 \text { min. } \\
18.0 \text { min. }\end{array}$ & $\begin{array}{l}15.0 \text { sec. } \\
45.0 \text { see. } \\
2.5 \text { min. } \\
3.0 \text { min. }\end{array}$ & $\begin{array}{l}20.0 \text { sec. } \\
45 \text { sec. } \\
2.5 \text { min. } \\
3.0 \mathrm{~min} . \\
3.5 \mathrm{~min} . \\
4.0 \mathrm{~min} . \\
6.0 \mathrm{~min} .\end{array}$ & $\begin{array}{l}20.0 \text { sec. } \\
1.0 \text { min. } \\
2.5 \text { min. } \\
4.0 \text { min. } \\
7.0 \text { min. }\end{array}$ & $\begin{array}{l}20 \text { sec. } \\
1 \mathrm{~min} . \\
5 \mathrm{~min} . \\
9 \mathrm{~min} .\end{array}$ & $\begin{array}{l}15 \text { sec. } \\
1 \text { min. } \\
8 \text { min. } \\
20 \text { min. }\end{array}$ & $\begin{array}{r}30 \mathrm{sec} . \\
2 \mathrm{~min} . \\
4 \mathrm{~min} . \\
7 \mathrm{~min} . \\
18 \mathrm{~min} .\end{array}$ \\
\hline
\end{tabular}


in these, as well as in other experiments, has shown itself to be remarkably resistant to high temperatures as compared with the ordinary races. In the second place, the temperature coefficient, $\mathrm{Q}_{1}$, in a given set of experiments is subject to far more variation than in the case of starfish larvae, being as a rule much higher (usually approximately 3 ) in the region above $40^{\circ}$ than in that below this temperature, and being subject at all times to considerable and sometimes inexplicable fluctuations. For this reason, calculations made by the method described are not so exact as in the case of the starfish larvae, but fortunately this is not necessary since Paramecium shows such a high degree of acclimatization that the error due to the simplifying assumption that the value, $Q_{1}=3$, applies to all temperatures is not able to disguise this fact. In other words, the error that arises from taking this value of $Q_{1}$ for the entire range, while, as a matter of fact, it is considerably less at lower temperatures, is of such a nature as simply to make the difference between the calculated and observed death points less striking than it would otherwise have been. If acclimatization is shown when such a simplifying assumption is made, it would a fortiori be indicated if more exact calculations had been made.

This point will be made clearer by an actual example. It was found in one set of experiments that for the three-vacuoled race, $\mathrm{Q}_{1}$ between $40^{\circ}$ and $43^{\circ}$ was equal to almost exactly 3.0. The length of life after a sudden exposure to $41^{\circ}$ was found to be 4.5 minutes, i.e., $I_{0}$ (taking this temperature as the standard of comparison) was equal to 0.22 . It was also found that when the animals were heated gradually, at the rate of $1^{\circ}$ in eight minutes, the observed death point was very close to $44^{\circ}$. The calculated death point, on the assumption that $\mathrm{Q}_{1}$ is equal to 3.0 for all temperatures is approximately $40.6^{\circ}$, a difference of $3.4^{\circ}$, indicating a very considerable amount of acclimatization. If instead of assuming that below $40^{\circ}$ the injury at any temperature in unit time is only one-third as great as that at the temperature one degree higher (as implied by the value, $Q_{1}=3$ ), we had taken into account the lower values of the temperature coefficient which usually apply to this region, it is clear that the amount of 
injury inflicted at the temperatures below $40^{\circ}$ would not drop off so rapidly, or, in other words, that the animals would be more injured during their gradual rise by the time they had reached $40^{\circ}$, and that consequently the calculated death temperature would be even lower than before. But this would only make stronger the evidence of acclimatization already obtained by the rough calculation.

It is of some interest not merely to show that acclimatization occurs, but to attempt to express its extent in quantitative form. This can be done in an approximate fashion by calculating the area enclosed by the given curve up to $\theta=44^{\circ}$ and comparing this area with that which represents unit injury, i.e., death. Such results, of course, are only rough approximations, but have nevertheless a considerable interest. Using the formula already given:

$$
I=t I_{0} \cdot \frac{Q_{i}^{p}}{\log _{e} Q_{1}}
$$

the area in the case just mentioned proves to be 44 units of injury. In other words, before death occurred, during the gradual rise, the animals had withstood about forty-four times the usual fatal injury. It is suggested that in this and in similar cases the excess in area enclosed by the curve of injury, up to the point of death, over the area (taken as unity) which represents an amount of injury just fatal when the change is sudden, may be called the surplus resistance, and be used as a rough quantitative measure of the extent of acclimatization. In this case the surplus resistance is equal to 43 . The animals have, in other words, added to their normal lives, so to speak, fortythree additional lives by their ability to adjust themselves to the changing environment.

The favorable effect of a slow as compared with a rapid rise of temperature on Paramecium is shown by another experiment in which method 3 was combined with method 2 . In this case, a tube of very small caliber $(3 \mathrm{~mm}$.) with extremely thin walls was prepared by drawing out the lower portion of a thin-walled test-tube in a flame to a considerable length and sealing the small 
end. Drops of water containing Paramecium could be placed in it and removed with a capillary pipette. It was found by the insertion of a thermocouple in such a drop of water and another in a vessel of water at $41^{\circ} \mathrm{C}$. into which the tube was plunged, that the water in the tube reached approximately the temperature of that in the surrounding vessel in about twenty seconds. This fact being known, a number of animals were placed in it and plunged into water at $41^{\circ}$ for two minutes and twenty seconds (giving therefore an exposure of two minutes at $41^{\circ}$ ). On removal, it was found that all were fatally injured. Another lot were placed in the same tube, but they were brought at a uniform rate from room temperature to $41^{\circ}$ in two minutes and then kept at exactly $41^{\circ}$ for two minutes longer. In this case about one-quarter of the individuals recovered. A third lot were treated in the same way except that in this case the rise to $41^{\circ}$ occupied twelve minutes. About one-half of these animals recovered. Doubtless a slower increase of temperature would have given even a higher percentage of recoveries. With starfish larvae, it may be mentioned, that experiments made in the same manner showed in every case exactly the reverse effect, i.e., the slower the rate of temperature increase, the higher the mortality.

A considerable number of other experiments were tried with Paramecium with the same general results as those mentioned. The degree to which a slow change increased the final resistance varied considerably with different races and under different experimental conditions, but in all cases it was very appreciable. It is apparent, therefore, that in the case of this organism, at least, the upper thermal death points that will be obtained in different experiments by the methods usually employed may be expected to be subject to considerable variations, which in many cases will be difficult to predict. To what extent the same principle will be found to apply in the case of other organisms can be determined only by further observations. In any event, however, the author believes that to be of value, data on the upper thermal death points of organisms must include not only the length of 
exposure to the particular fatal temperature under consideration, but in addition, an exact statement of the manner in which this temperature was reached.

\section{SUMMARY}

1. The length of life of starfish larvae eighteen to forty-eight hours old at temperatures between $32^{\circ}$ and $40^{\circ} \mathrm{C}$. is governed with a very fair degree of accuracy by the relation:

$$
\frac{\mathrm{L}_{\theta}}{\mathrm{L}_{\theta+1}}=\mathrm{Q}_{1}=\text { approximately } 2 \text {. }
$$

For Paramecium, the value of $\mathrm{Q}_{1}$ is subject to considerably more variation; above $40^{\circ} \mathrm{C}$. it is frequently in the vicinity of 3 ; below $40^{\circ}$ often less than 2 .

2. Knowing the above relation and the length of life after a sudden exposure to one or more selected temperatures, it is possible to calculate by the method given in the body of the paper the point at which death ought theoretically to occur when the temperature is raised uniformly at any given rate. By comparing this point with the observed death point under the same conditions, it can usually be determined whether or not acclimatization has occurred.

3. With the different rates of temperature increase employed in these experiments the observed death points of starfish larvae agree very closely with the calculated ones, indicating practically no acclimatization. With Paramecium caudatum the observed death point may be much higher than the calculated one, indicating that acclimatization occurs even in experiments of short duration.

4. If desired, the 'surplus resistance' in a given experiment may be obtained in quantitative form by determining the excess in area enclosed by the curve of injury up to the point of death, over the area (taken as unity) which represents an amount of injury just fatal when the temperature is changed suddenly.

5. As determined in this way, the 'surplus resistance' for starfish larvae for a number of different rates of increase of tempera- 
ture was found to be in the vicinity of zero. For Paramecium caudatum, on the other hand, a 'surplus resistance' as high as 43 has been found.

6. In general, the slower rates of temperature increase are more favorable for Paramecium and more unfavorable for starfish larvae than the more rapid ones.

7. It is suggested that future data on upper thermal death points, etc., shall include not only the times of exposure to the temperatures in question, but exact statements as to the methods by which these temperatures have been reached.

\section{LITERATURE CITED}

Davenpost, C. B. 1897 Experimental Morphology. New York. Vol. 1.

HANCE, R. T. 1915 The inheritance of extra contractile vacuoles in an unusual race of Paramecium caudatum. Science, N.S., 42.

1917 Studies on a race of Paramecium caudatum possessing extra contractile vacuoles. Jour Exp. Zoöl., vol. 23.

Kanitz, A. 1915 Temperatur und Lebensvorgänge. Berlin.

LOEB, J. 1908 Über den Temperaturkoeffizienten für die Lebensdauer kaltblütiger Tiere und über die Ursache des natürlichen Todes. Pflüger's Archiv, 124.

Moore, A. R. 1910 The temperature coefficient of the duration of life in Tubularia crocea. Arch. Entwick., Bd. 29. 